\title{
Comparison of Binding Parameter Constants between Sevelamer HCl Tablets and Renagel Tablets by a Validated Inductively Coupled Plasma-Optical Emission Spectrometry (ICP-OES) Method
}

\author{
Venkata Vivekanand Vallapragada ${ }^{1,2^{*}}$, Gopichand Inti ${ }^{1}$, Ajay Kanyadhara ${ }^{1}$, \\ Sudhakar Rao Vidiyala ${ }^{1}$, Sreeramulu Jadi $^{2}$ \\ ${ }^{1}$ Invagen Pharmaceutical Inc., Hauppauge, USA \\ ${ }^{2}$ Department of Chemistry, Sri Krishna Devaraya University, Anantapur, India \\ Email: *vvviveka@yahoo.com
}

Received October 31, 2012; revised December 3, 2012; accepted December 10, 2012

\begin{abstract}
Sevelamer Hydrochloride is a crossolinked polymeric amine; it is the active ingredient in Renagel Tablets. Sevelamer Hydrochloride is indicated for the control of hyperphosphatamiea in patients with end-stage renal disease. The binding parameter constants of Sevelamer Hydrochloride were determined using the Langmuir approximation for the dosage form at $\mathrm{pH} 4.0$ and 7.0 by Inductively Coupled Plasma-Optical Emission Spectrometry. An ICP-OES method has been developed to estimate free phosphate in in-vitro phosphate binding study of Sevelamer HCl Tablets. The method is selective and capable of detecting phosphate in the presence of placebo matrix. The method has been validated with a lower limit of quantitation of $0.2 \mathrm{mM}$ for Phosphate. A linear response function was established for the range of concentrations 0.2 - $25.0 \mathrm{mM}$ ( $\mathrm{r}>0.99$ ) for Phosphate. The intra and inter day precision values for Phosphate met the acceptance as per Food and Drug Administrations guidelines. Phosphate was stable in the set of stability studies viz. bench-top and autosampler. The developed method was applied to in-vitro phosphate binding studies of Sevelamer $\mathrm{HCl}$ Tablets.
\end{abstract}

Keywords: Binding Parameter Constants; ICP-OES; In-Vitro Phosphate Binding Study; Langmuir Approximation; Renagel Tablets; Quantitation

\section{Introduction}

Sevelamer Hydrochloride is the active ingredient in Renagel tablets. Sevelamer Hydrochloride, a cross-linked poly (allylamine hydrochloride), is a novel phosphate binder used for the reduction of serum phosphate levels in patients with end-stage renal disease (ESRD) [1-6]. The advantage of Sevelamer Hydrochloride for ESRD over existing therapies, such as calcium or aluminum supplementation, is that it is a non-absorbed, leading to an improved safety profile. There is evidence that treatment with Sevelamer hydrochloride leads to the attenuation of the progression of coronary artery and aortic calcification as well as improved control of parathyroid hormone levels relative to calcium salts [7]. The structure of Sevelamer Hydrochloride is shown in Figure 1.

Aluminum is widely recognized as the cost effective phosphate-binding drug but its use is now generally restricted to ESRD patients who are uncontrolled on other

*Corresponding author. agents, owing to concerns about its toxicity, including dialysis encephalopathy, osteomalacia and microcytic anaemia [8-12]. Calcium-based binders largely replaced aluminum in the 1980s and 1990s and have been mainstay of treatment for many years [13]. However, large doses are needed with each meal leading to concerns about elevated calcium load, hypercalcaemia, and an increased potential for vascular calcification [14-16]. For this reason, current Kidney Disease Outcomes Quality Initiative (KDOQI) guidelines recommend restricting the total dose of elemental calcium provided by calcium binders to less than $1500 \mathrm{mg}$ /day in Stage 5 chronic kidney disease (CKD) patients [17].

The introduction of Sevelamer Hydrochloride a cationic hydrogel of cross-linked poly (allylamine hydrochloride) that does not contain aluminum or calcium (third-generation binder) was a significant advance, enabling reduction of serum phosphate without adding to the patient's calcium load [18]. 


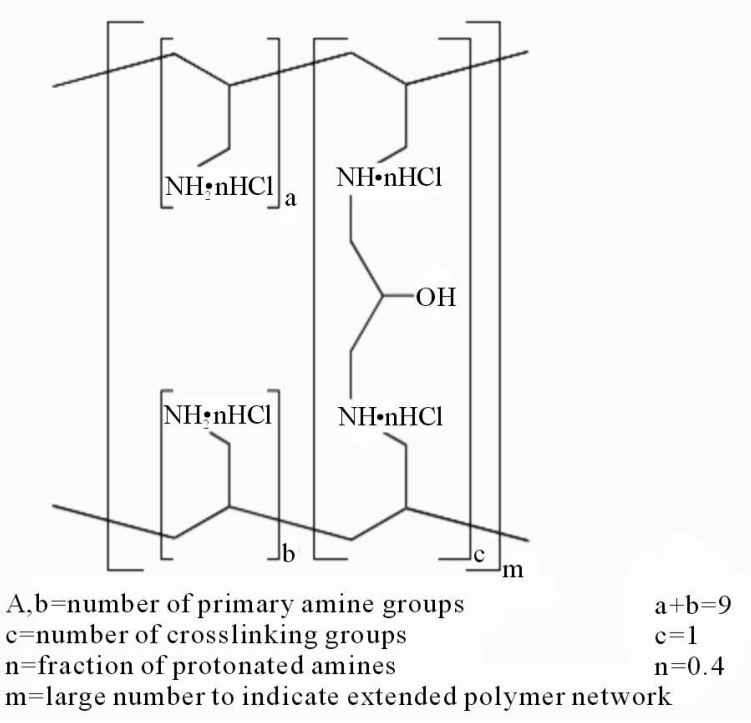

Figure 1. Structure of sevelamer hydrochloride.

We have come across a similar publication on determination of the binding parameter constant of Renagel capsules and tablets utilizing the Langmuir approximation at various $\mathrm{pH}$ by ion chromatography and capillary electrophoresis. However we did not find any publication giving details determining the binding parameter constants by Inductively Coupled Plasma-Optical Emission Spectrometry (ICP-OES). On the other hand capillary electrophoresis and ion chromatography methods are not so rugged to analyze the in-vitro phosphate binding samples of Renagel Tablets. Bigger analytical batch runs are not suitable in Ion Chromatography technique and Capillary Electrophoresis techniques where we might face system suitability failures and poor peak shapes. Hence we developed a suitable ICP-OES method to estimate free phosphate in Renagel Tablets.

ICP-OES has additional advantages over the other techniques in terms of detection limits as well as speed of analysis. An ICP-OES sample experiences temperature estimated to be in the vicinity of $10,000 \mathrm{~K}$. This results in atomization and excitation of even most refractory elements with high efficiency so that detection limits for these elements with ICP-OES can be well over and order of magnitude better than the corresponding values of other techniques. The limit of quantitation values of most elements in ICP-OES in part per million and even parts per billion. In number of analytical applications speed can be an important factor. ICP-OES is one of the best techniques due to its rapid analysis time and reliability of results $[19,20]$.

An important aspect of the analytical characterization of Sevelamer hydrochloride tablets is to demonstrate equivalency to the tablet dosage form. The amines in Sevelamer Hydrochloride may bind phosphate ionically and through hydrogen bonding.

This paper describes the methodology and procedures for the determination the binding constants at two different $\mathrm{pH}$ levels utilizing the Langmuir approximation. A comparison of these binding constants demonstrates the equivalency of tablet dosage form at each $\mathrm{pH}$ studied. The binding study has been done on Brand tablets (Renagel Tablets $800 \mathrm{mg}$ ) as well as Sevelamer $\mathrm{HCl}$ Tablets $800 \mathrm{mg}$ produced at Invagen Pharmaceutical Inc. The binding study has been performed using the phosphate $\left(\mathrm{KH}_{2} \mathrm{PO}_{4}\right)$ buffer solutions of $1 \mathrm{mM}, 2.5 \mathrm{mM}, 5.0$ $\mathrm{mM}, 7.5 \mathrm{mM}, 10.0 \mathrm{mM}, 14.5 \mathrm{mM}, 30.0 \mathrm{mM}$ and 38.7 $\mathrm{mM}$ at two different buffers $\mathrm{pH} 4.0$ and 7.0. The method used for this study has been validated in terms of Precision, Linearity, accuracy, Limit of Quantitation and Robustness. The complete validation data demonstrates the intended purpose of the method in estimating the binding parameter constants of the Sevelamer $\mathrm{HCl}$ tablets.

\section{Materials and Methods}

\subsection{Chemicals}

Sevelamer Hydrochloride was obtained from Shasun Pharmaceuticals Ltd. (Chennai, India), N,N-Bis(hydroxyethyl)-2-aminoethanesulfonic acid (BES) was obtained from Sigma Chemical Company (USA), Potassium phosphate monobasic $\left(\mathrm{KH}_{2} \mathrm{PO}_{4}\right)$ and $1 \mathrm{~N}$ aqueous sodium hydroxide were obtained from Spectrum Chemicals (USA). Sodium hydroxide pellets were from Spectrum Chemicals (USA). Deionised water was obtained from an in-house TOC water system (Sievers, USA). Renagel tablets purchased commercially which is manufactured by Genzyme pharmaceuticals Inc (USA). Sevelamer $\mathrm{HCl}$ Tablets 800 mg from Invagen Pharmaceutical Inc.

\subsection{Equipment}

A Perkin Elmer Inductively coupled Plasma system equipped with Optical Emission Spectrophotometer and system controlled through Win Lab32 software. The incubator used for the experiment is Max Q 4000 of Thermo Scientific.

\subsection{ICP-OES Conditions}

The RF power was used 1500 watts, Plasma flow was used $15 \mathrm{~L} / \mathrm{min}$, Auxillary Flow was kept at $0.2 \mathrm{~L} / \mathrm{min}$, Nebuliser Flow was kept at $0.8 \mathrm{~L} / \mathrm{min}$, Pump Rate was kept at $1.5 \mathrm{ml} / \mathrm{min}$, Phosphate was monitored at wavelength of 213.617 and plasma view was in axial mode.

\subsection{Validation of the Method}

\subsubsection{Selectivity}

Selectivity is the ability of an analytical method to dif- 
ferentiate and quantify the analyte in the presence of other components in the sample. Six independent blanks and six independent placebo preparations were analyzed for possible interference of matrix with the analyte (Phosphate). LOQ solution ( $0.2 \mathrm{mM}$ ) was aspirated along with the blank and placebo solutions at $213.617 \mathrm{~nm}$ into ICP-OES to check the interference of any other elements at that particular wavelength (Figure 2).

\subsubsection{Placebo Binding Check}

Placebo solution is checked for any binding with media that affects the selectivity of method. Six independent solutions of Placebo equivalent to one dosage unit of Sevelamer $\mathrm{HCl}$ Tablet were prepared in $1.0 \mathrm{mM} \mathrm{KH_{2 }} \mathrm{PO}_{4}$ and $38.7 \mathrm{mM} \mathrm{KH}_{2} \mathrm{PO}_{4}$ respectively, to check the possible binding of placebo.

\subsubsection{Calibration Curve}

The calibration curve for free phosphate determination consists of a Calibration blank and six non-zero calibration standards covering concentrations ranging from 0.2 $\mathrm{mM}$ to $25.0 \mathrm{mM}$ of Monobasic Potassium Phosphate buffer $(0.2,1.0,5.0,10.0,14.5 \& 25.0 \mathrm{mM})$. Analyte corrected peak intensity values were used to set up the calibration curve and to determine QC sample concentrations. Linear Regression with linearity through zero was used to obtain the best fit of the data for the calibration curve. The acceptance criteria for each back-calculated standard concentration were $\pm 15 \%$ deviation from the nominal value except a LLOQ, which was set at $\pm 20 \%$. Calibration curve standards and quality control samples met the acceptance criteria for all experiments used in the final data, demonostrating satisfactory performance of the method during validation.

\subsubsection{Precision and Accuracy}

The intra-assay precision and accuracy were estimated by analyzing replicates of Phosphate buffer solutions at four different QC levels, i.e. 0.2 (LLOQ), 0.6 (LQC), 1.5 (MQC) and 20.0 (HQC) mM. The inter assay precision was determined by analyzing the four levels QC samples on three different runs. The criteria for acceptability of the data included accuracy within $\pm 15 \%$ standard deviation (SD) from the nominal values and a precision of within $\pm 15 \%$ relative standard deviation (RSD) except for LLOQ, where it should not exceed 20\% RSD (Table 1).

\subsubsection{Stability}

The bench top stability and auto sampler stability was determined by analysing six Tablets of Sevelamer $\mathrm{HCl}$ incubated in low $(1.0 \mathrm{mM})$ and high $(38.7 \mathrm{mM})$ concentrations of Phosphate buffer at $\mathrm{pH} 4.0$ and 7.0. As per the experimental conditions, samples were analyzed initially (0 hour), after 24 hours and 48 hours with freshly prepared calibration standards and two replicates of each low, medium and high QC's.

\subsubsection{Robustness}

Robustness is defined as degree of reproducibility of results obtained when various experimental conditions were altered such as RPM, Temperature and $\mathrm{pH}$. Robustness is established by analyzing three tablets of Sevelamer $\mathrm{HCl}$ incubated in low $(1 \mathrm{mM})$ and high (38.7 $\mathrm{mM}$ ) concentrations of Phosphate buffers by altering the RPM (150, $200 \& 250)$, Temperature $\left(34.0^{\circ} \mathrm{C}, 37.0^{\circ} \mathrm{C}\right.$ and $\left.40.0^{\circ} \mathrm{C}\right)$ and $\mathrm{pH}(6.80,7.00 \& 7.20,3.80,4.00 \&$ 4.20). The free phosphate is estimated with freshly prepared calibration standards and two sets of QC's.

\subsubsection{Phosphate Binding Plateau}

The study was performed in $38.7 \mathrm{mM}$ phosphate buffer with 6 tablets of Renagel Tablets $800 \mathrm{mg}$ in $300 \mathrm{ml}$ of $38.7 \mathrm{mM}$ buffer solution at $\mathrm{pH} 4.0$ and $7.0 .10 \mathrm{ml}$ of sample was withdrawn from each vessel at time intervals

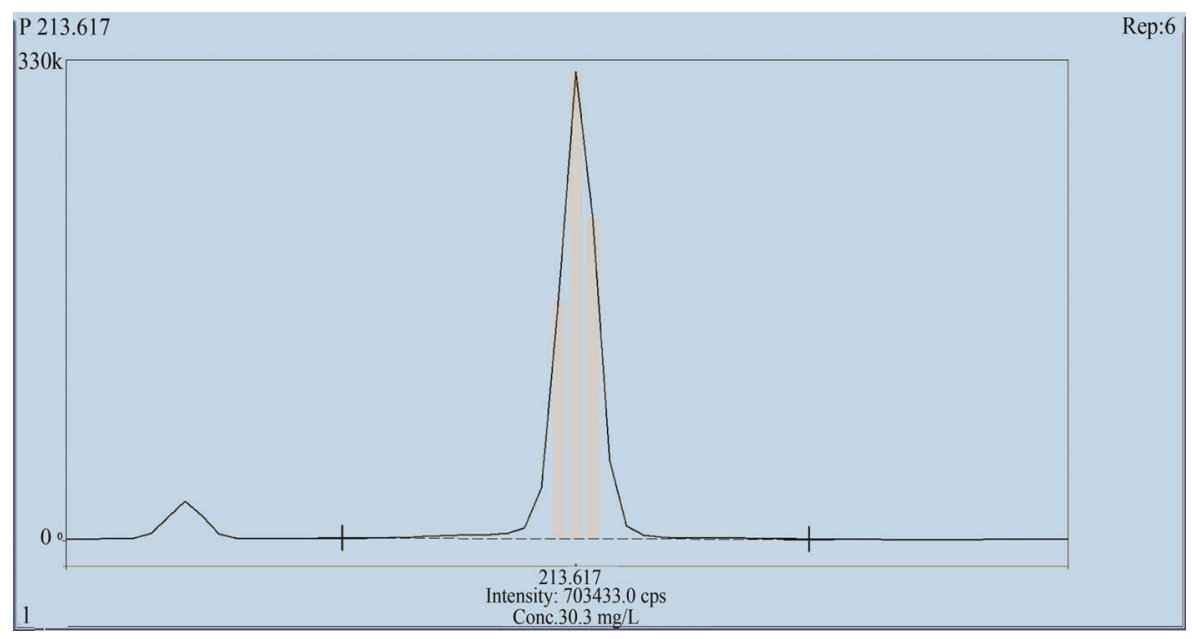

Figure 2. Typical ICP spectra of phosphate at $213.677 \mathrm{~nm}$. 
Table 1. Intra and Inter-day precision determination Quality Control samples.

\begin{tabular}{|c|c|c|c|c|c|}
\hline \multicolumn{6}{|c|}{ Intraday variation (six replicates at each concentration) } \\
\hline Theoretical Concentration (mM) & Run & $\begin{array}{l}\text { Average measured concentration } \\
(\mathbf{m M})\end{array}$ & SD & RSD & Accuracy (\%) \\
\hline & 1 & 0.209 & 0.0004 & 0.2 & 104.5 \\
\hline \multirow[t]{3}{*}{0.2} & 2 & 0.207 & 0.0008 & 0.4 & 103.5 \\
\hline & 3 & 0.204 & 0.0015 & 0.7 & 102.0 \\
\hline & 1 & 0.615 & 0.0025 & 0.4 & 102.5 \\
\hline \multirow[t]{3}{*}{0.6} & 2 & 0.608 & 0.0019 & 0.3 & 101.3 \\
\hline & 3 & 0.604 & 0.0018 & 0.3 & 100.7 \\
\hline & 1 & 1.542 & 0.0116 & 0.8 & 102.8 \\
\hline \multirow[t]{3}{*}{1.5} & 2 & 1.532 & 0.0248 & 1.6 & 102.1 \\
\hline & 3 & 1.503 & 0.0051 & 0.3 & 100.2 \\
\hline & 1 & 20.167 & 0.1751 & 0.9 & 100.8 \\
\hline \multirow[t]{2}{*}{20.0} & 2 & 19.967 & 0.1032 & 0.5 & 99.8 \\
\hline & 3 & 19.650 & 0.1516 & 0.8 & 98.3 \\
\hline \multicolumn{6}{|c|}{ Inter-day variation (18 replicates at each concentration) } \\
\hline 0.2 & & 0.207 & 0.0025 & 1.2 & 103.5 \\
\hline 0.6 & & 0.609 & 0.0055 & 0.9 & 101.5 \\
\hline 1.5 & & 1.526 & 0.0202 & 1.3 & 101.7 \\
\hline 20.0 & & 19.928 & 0.2606 & 1.3 & 99.6 \\
\hline
\end{tabular}

of $15,30,45,60,90,120,150$ and 180 min's. The samples were filtered through $0.45 \mu \mathrm{m}$ filters and analyzed on ICP-OES for binding plateau. The Phosphate binding was calculated at each interval, and found to be similar at all the time intervals (Figure 3).

\subsection{In-Vitro Phosphate Binding Study}

\subsubsection{Equilibrium Binding}

In-vitro phosphate binding study was performed on Renagel Tablets $800 \mathrm{mg}$ (Genzyme) and Sevelamer HCl Tablets $800 \mathrm{mg}$ (Invagen). Two individual sets of aqueous phosphate solutions were prepared at the following concentration $38.7 \mathrm{mM}, 30.0 \mathrm{mM}, 14.5 \mathrm{mM}, 10.0 \mathrm{mM}$, $7.5 \mathrm{mM}, 5.0 \mathrm{mM}, 2.5 \mathrm{mM}$ and $1.0 \mathrm{mM}$. Each set of phosphate solutions were prepared so that a final $\mathrm{pH}$ of 4.0 and 7.0 was obtained after the addition of Renagel tablets, as described below. All solutions contained 100 $\mathrm{mM} \mathrm{BES}$ and $80 \mathrm{mM} \mathrm{NaCl}$.

The entire study has been done with Sevelamer $\mathrm{HCl}$ Tablets $800 \mathrm{mg}$ with $300 \mathrm{ml}$ volume of the phosphate buffer solution. The solutions at $\mathrm{pH} 4.0$ were prepared by adding the tablets to a set of phosphate solutions, which had no prior $\mathrm{pH}$ adjustments. Upon their disintegration, approximately $3 \mathrm{ml}$ of $1 \mathrm{~N} \mathrm{HCl}$ is added for $1.0 \mathrm{mM}$ to $14.5 \mathrm{mM}$ buffer solutions, where as $5 \mathrm{ml}$ was added to $30.0 \mathrm{mM}$ and $38.7 \mathrm{mM}$ buffer solutions. The $\mathrm{pHs}$ of the final solutions were approximately 4.0.

The solutions at $\mathrm{pH} 7.0$ were prepared by adjusting the $\mathrm{pH}$ of each solution to 7.0 with $1 \mathrm{~N} \mathrm{NaOH}$. Approximately $50 \mathrm{ml}$ of $1 \mathrm{~N} \mathrm{NaOH}$ was volumetrically added per liter of solution. After the addition of the tablets the $\mathrm{pH}$ of the solution was approximately 7.0. Twelve tablets of Renagel and Sevelamer $\mathrm{HCl}$ were utilized at each buffer concentration. The $\mathrm{pH}$ of this solution does not change because the $\mathrm{pK}_{\mathrm{a}}$ of BES is 7.1 and thus provides excellent buffering capacity in this $\mathrm{pH}$ range. BES was utilized throughout this experiment so that a direct comparison of all results is possible. It has been demonstrated that BES, in concentrations from 60 to $120 \mathrm{mM}$, does not affect the phosphate binding.

All the samples were then placed on a Max Q 4000 incubator shaker at $37^{\circ} \mathrm{C}$ for 2 hours. The samples were removed, filtered through a $0.45 \mu \mathrm{m}$ nylon syringe filter. The samples are analyzed with the established calibration curve along with QC samples at low, medium and high concentrations were assayed in duplicate and were distributed among unknown samples in the analytical run. 


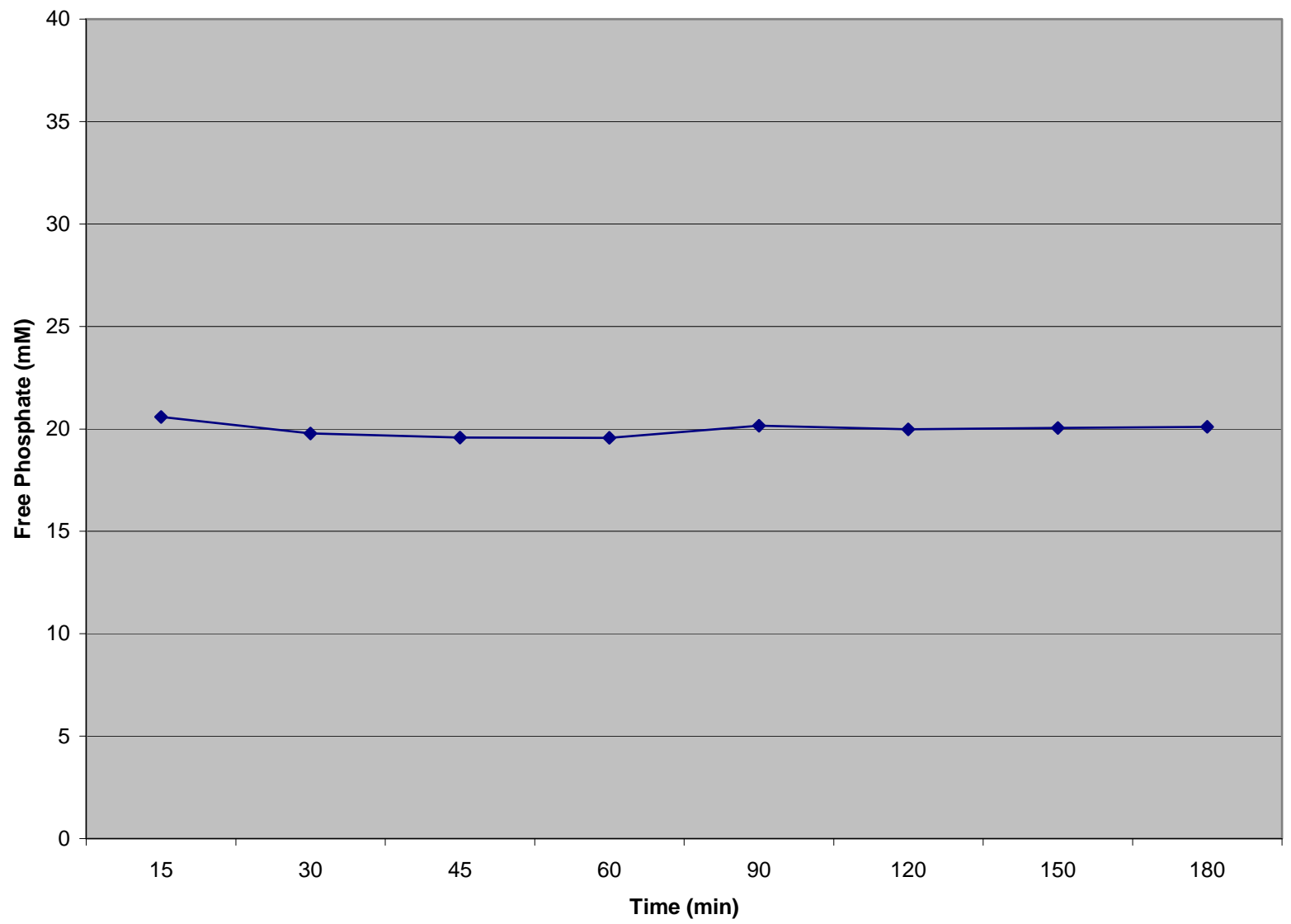

Figure 3. Phosphate binding plateau of renagel tablets $800 \mathrm{mg}$ at $\mathrm{pH} 4.0$.

A calibration curve was generated at each $\mathrm{pH}$ to produce a total of two separate 6 point calibration curves for quantitation at $\mathrm{pH} 4.0$ and 7.0. The area of the phosphate peak versus the concentration was plotted and the coefficient of determination values for each curve was greater than 0.998 .

\subsection{Calculations}

The unbound phosphate concentrations remaining in each sample were calculated from the linear regression generated from a plot of the area of the phosphate peak versus the concentration of phosphate $(\mathrm{mM})$ using the following equation:

$$
\begin{aligned}
& \text { Unbound phosphate concentration }(\mathrm{mM}) \\
= & \frac{\text { Area of phosphate }- \text { intercept }}{\text { Slope }}
\end{aligned}
$$

From the known initial concentration of phosphate in each solution before the addition of Sevelamer Hydrochloride (i.e. $38.7 \mathrm{mM}, 30.0 \mathrm{mM}, 14.5 \mathrm{mM}, 10.0 \mathrm{mM}$, $7.5 \mathrm{mM}, 5.0 \mathrm{mM}, 2.5 \mathrm{mM}$ and $1.0 \mathrm{mM}$ ) the bound concentration was calculated by subtracting the unbound concentration from the initial concentration.

Bound phosphate concentration $(\mathrm{mM})=$ initial concen- tration (mM)-Unbound phosphate concentration (mM)

The phosphate binding capacity, in mmol of phosphate/g of polymer, was calculated as follows:

$$
\begin{aligned}
& \text { Phosphate binding capacity (mmol/g) } \\
& =\frac{\text { bound phosphate concentration }(\mathrm{mM}) \times \mathrm{Vs}}{\text { Weight }(\mathrm{g})}
\end{aligned}
$$

where Vs is the volume of solution, approximately $0.3 \mathrm{~L}$

The weight ( $\mathrm{g}$ ) is the weight of Sevelamer Hydrochloride.

The phosphate binding constants were calculated from the Langmuir approximation. The monomolecular adsorption of an adsorbate (phosphate) from solution, at constant temperature, onto an adsorbent (Sevelamer Hydrochloride). This process is described by the Langmuir equation:

$$
\frac{\mathrm{C}_{\text {eq }}}{\mathrm{x} / \mathrm{m}}=\frac{1}{\mathrm{k}_{1} \mathrm{k}_{2}}+\frac{\mathrm{C}_{\mathrm{eq}}}{\mathrm{k}_{2}}
$$

where $\mathrm{C}_{\mathrm{eq}}$ is the concentration, in $\mathrm{mM}$ of phosphate remaining in solution at equilibrium or the unbound concentration. $\mathrm{x} / \mathrm{m}$ is the amount of phosphate bound per weight of polymer in $\mathrm{mmol} / \mathrm{g}$. The constant $\mathrm{k}_{1}$ is the 
affinity constant and is related to the magnitude of the forces, which are involved in binding. The constant $k_{2}$ is the Langmuir capacity constant and is the maximum amount of phosphate that can be bound per unit weight of Sevelamer Hydrochloride.

The affinity and Langmuir capacity constants were calculated by performing linear regression on a plot of the unbound $(\mathrm{mM}) / \mathrm{bound}(\mathrm{mmol} / \mathrm{g})$ versus the unbound $(\mathrm{mM})$ concentrations. The $\mathrm{k}_{1}$ value is calculated by dividing the slope of the regression line by the intercept, the $\mathrm{k}_{2}$ value is equal to the inverse of the slope (Figures $\mathbf{4}$ and $\mathbf{5}$, Table 2).

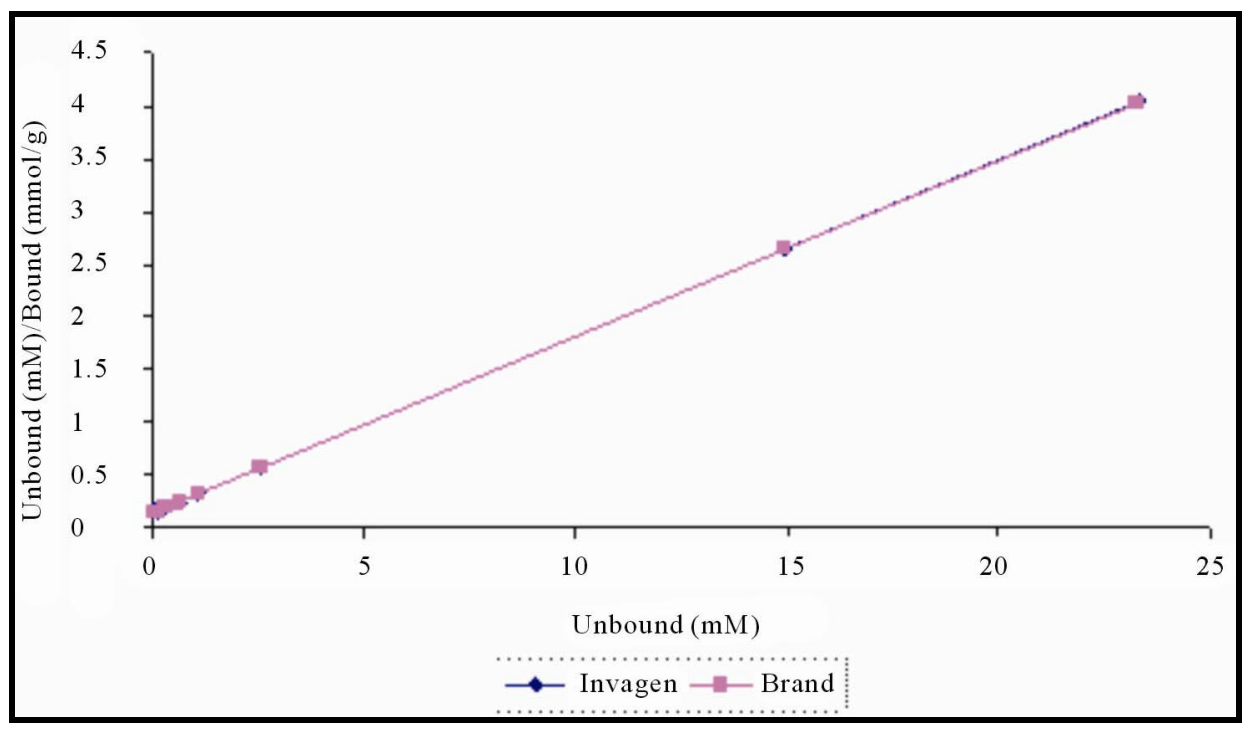

Figure 4. Langmuir plot of Sevelamer HCl Tablets $800 \mathrm{mg}$ (Invagen) and Renagel Tablets (Brand) $800 \mathrm{mg}$ at pH 7.0.

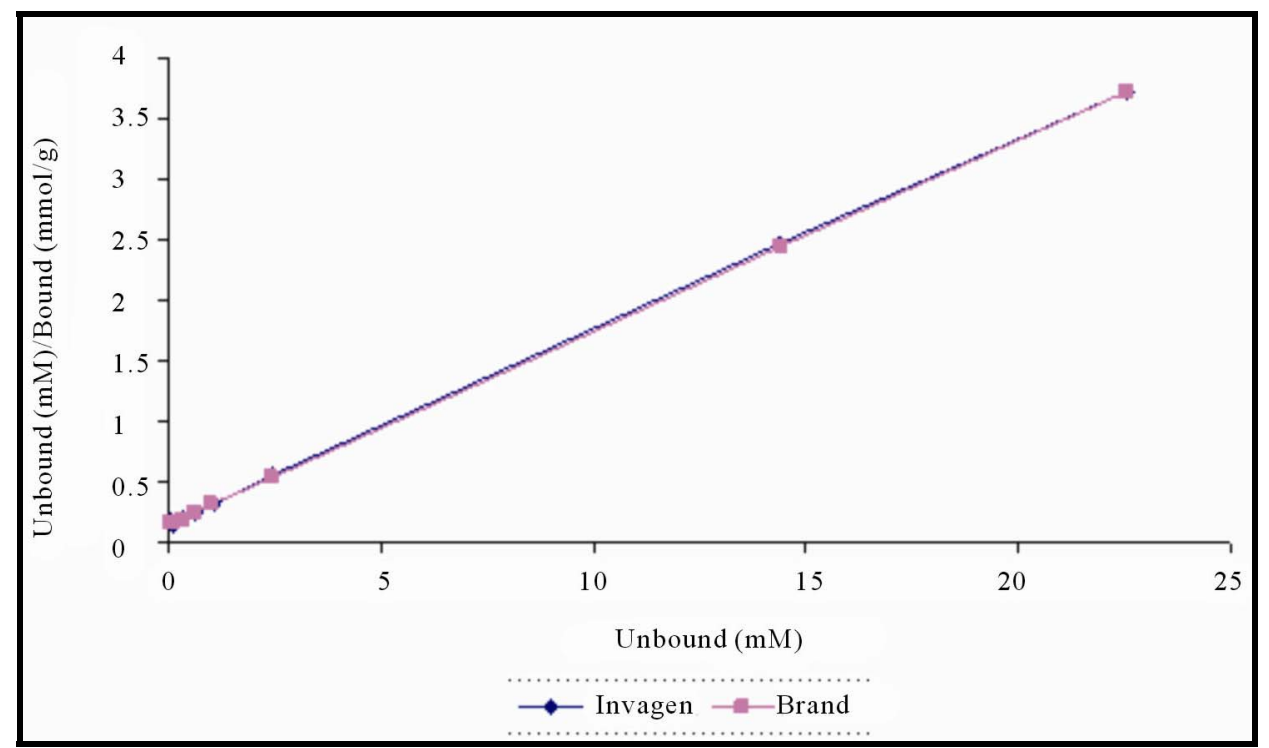

Figure 5. Langmuir plot of Sevelamer HCI Tablets 800 mg (Invagen) and Renagel Tablets 800 mg (Brand) at pH 4.0.

Table 2. The affinity and Langmuir capacity constants calculated at two pH levels.

\begin{tabular}{|c|c|c|c|c|c|c|c|c|c|}
\hline \multirow{2}{*}{ Buffer solutions } & \multicolumn{2}{|c|}{$\begin{array}{l}\text { Sevelamer HCl } \\
\text { Tablets } 800 \text { mg }\end{array}$} & \multicolumn{2}{|c|}{$\begin{array}{l}\text { Renagel Tablets } \\
\quad 800 \mathrm{mg}\end{array}$} & \multicolumn{3}{|c|}{$\mathrm{K}_{1}$ (Slope/Intercept) } & \multicolumn{2}{|c|}{$K_{2}$ (1/Slope) } \\
\hline & Slope & Intercept & Slope & Intercept & $\begin{array}{l}\text { Invagen } \\
\text { (T) }\end{array}$ & $\begin{array}{l}\text { Brand } \\
\text { ( R ) }\end{array}$ & $\begin{array}{c}\text { T/R } \\
\text { Ratio }\end{array}$ & Invagen & Brand \\
\hline pH 7.0 & 0.167 & 0.144 & 0.167 & 0.142 & 1.159 & 1.176 & 98.554 & 5.988 & 5.988 \\
\hline $\mathrm{pH} 4.0$ & 0.159 & 0.171 & 0.158 & 0.171 & 0.929 & 0.923 & 100.65 & 6.289 & 6.329 \\
\hline
\end{tabular}




\section{Discussion}

The results demonstrate that at each $\mathrm{pH}$, no significant change observed in the Langmuir capacity constant $\left(\mathrm{k}_{2}\right)$ and affinity constant $\left(\mathrm{k}_{1}\right)$ was observed in Sevelamer $\mathrm{HCl}$ Tablets $800 \mathrm{mg}$ when compared with the Brand product (Renagel Tablets $800 \mathrm{mg}$ ). Sevelamer $\mathrm{HCl}$ is binds phosphate by ion exchange of chloride by phosphate from a solid polymer [Equation (1)]. Therefore, the absolute binding capacity is difficult to predict because it depends on the degree of ion exchange varies in the presence of the placebo matrix.

$$
\begin{aligned}
& \mathrm{R}-\mathrm{NH}_{3}^{+} \mathrm{Cl}^{-}(\mathrm{s})+\mathrm{H}_{2} \mathrm{PO}_{4}^{-}(\mathrm{aq}) \\
& \longrightarrow \mathrm{R}^{-} \mathrm{NH}_{3}^{+} \mathrm{H}_{2} \mathrm{PO}_{4}^{-}(\mathrm{s})+\mathrm{Cl}^{-}(\mathrm{aq})
\end{aligned}
$$

\section{Conclusions}

A validated ICP-OES method has been developed to estimate binding parameters constants in Sevelamer $\mathrm{HCl}$ tablets. The method is selective and is capable, to detect unbound phosphate quantitatively in the binding study. The method has been validated in terms of selectivity, precision, linearity, accuracy, limit of quantification and robustness. The validated method can be used to estimate phosphate in in-vitro studies of Sevelamer HCl Tablets. The determinations of binding parameter constants were compared between Renagel Tablets (Brand) and Sevelamer HCl Tablets (Invagen) and results are in good agreement.

\section{Acknowledgements}

The authors wish to thank the management of Invagen pharmaceutical Inc. for supporting this work. We would also like to thank colleagues in analytical development of Invagen pharmaceutical Inc. for their co-operation in carrying out this work.

\section{REFERENCES}

[1] D. Rosenbaum, S. Holmes-Farley, W. Mandeville, M. Pitruzello and D. Goldberg, "Effect of Renagel, a NonAbosrbable, Cross-Linked, Polymeric Phosphate Binder, on Urinary Phosphorus Excretion in Rats,” Nephrology Dialysis Transplantation, Vol. 12, No. 5, 1997, pp. 961964. doi:10.1093/ndt/12.5.961

[2] G. Chertow, S. Burke and J. Lazarus, "Poly Allylamine Hydrochloride (Renagel): A Noncalcemic Phosphate Binder for the Treatment of Hyperphosphatemia in Chronic Renal Failure,” American Journal of Kidney Diseases, Vol. 27, No. 1, 1997, pp. 66-71. doi:10.1016/S0272-6386(97)90009-3

[3] S. Burke, E. Slatopolsky and D. Goldberg, "Renagel, a Novel Calcium- and Aluminium-Free Phosphate Binder, Inhibits Phosphate Absorption in Normal Volunteers," Nephrology Dialysis Transplantation, Vol. 12, No. 8,
1997, pp. 1640-1644. doi:10.1093/ndt/12.8.1640

[4] R. A. Swearingen, X. Chen, J. S. Petersen, K. S. Riley, D. Wang and E. Zhorov, "Determination of the Binding Parameter Constants of Renagel Capsules and Tablets Utilizing the Langmuir Approximation at Various PH by Ion Chromatography," Journal of Pharmaceutical and Biomedical Analysis, Vol. 29, No. 1-2, 2002, pp. 195-201. doi:10.1016/S0731-7085(02)00007-9

[5] J. Mazzeo, R. Peters, M. Hanus, X. Chen and K. Norton, "A Phosphate Binding Assay for Sevelamer Hydrochloride by Ion Chromatography," Journal of Pharmaceutical and Biomedical Analysis, Vol. 19, No. 6, 1999, pp 911915. doi:10.1016/S0731-7085(98)00193-9

[6] S. R. Holmes-Farley, W. H. Manderville and K. L. Miller, "Design and Characterization of Sevelamer Hydrochloride: A Novel Phosphate-Binding Pharmaceutical,” Journal of Macromolecular Science: Pure and Applied Chemistry, Vol. 36, No. 7-8, 1999, pp. 1085-1091.

[7] G. M. Chertow, S. K. Burke, P. Raggi, et al., "Sevelamer Attenuates the Progression of Coronary and Aortic Calcification in Hemodialysis Patients,” Vol. 26, No. 1, 2002, pp. 245-252. doi:10.1046/j.1523-1755.2002.00434.X

[8] A. C. Alfrey, G. R. LeGendre and W. D. Kaehny, "The Dialysis Encephalopathy Syndrome, Possilbe Aluminum Intoxication," The New England Journal of Medicine, Vol. 294, No. 4, 1976, pp. 1184-1188. doi:10.1056/NEJM197601222940402

[9] I. S. Parkinson, M. K. Ward and D. N. Kerr, "Dialyis Encephalopathy, Bone Disease and Anaemia: The Aluminum Intoxication Syndrome Duringregular Haemodialysis,” Journal of Clinical Pathology, Vol. 34, No. 11, 1981, pp. 1285-1294. doi:10.1136/jcp.34.11.1285

[10] J. J. Plachot, G. Cournot-Witmer, S. Halpern, V. Mendes, A. Bourdeau, J. Fritsch, R. Bourdon, T. Drueke, P. Galle and S. Balsan, "Bone Ultrastructure and X-Ray Microanalysis of Alumimum-Intoxicated Hemodialyzed Patients,” Kidney International, Vol. 25, No. 5, 1984, pp. 796-803. doi:10.1038/ki.1984.92

[11] H. H. Malluche and M. C. Monier-Faugere, "Risk of Adynamic Bone Disease in Dialyzed Patients,” Kidney International, Vol. 42, Suppl. 38, 1992, pp. S62-S67.

[12] M. Touam, F. Martinez, B. Lacour, R. Bourdon, J. Zingraff, S. Di Giulio, T. Drueke, “Aluminium-Induced, Reversible Microcytic Anemia in Chronic Renal Failure: Clinical and Experimental Studies," Clinical Nephrology, Vol. 19, No. 6, 1983, pp. 295-298.

[13] M. Wallot, K. E. Bonzel, A. Winter, B. Georger, B. Lettgen and M. Bald, "Calcium Acetate versus Calcium Carbonate as Oral Phosphate Binder in Pediatric and Adolescent Hemodialysis Patients," Pediatric Nephrology, Vol. 10, No. 5, 1996, pp. 625-630. doi:10.1007/s004670050175

[14] W. G. Goodman, J. Goldin, B. D. Kuizon, B. Yoon Cm Gales, D. Sider, Y. Wang, J. Chung, A. Emerick, L. Greaser, R. M. Elashoff and I. B. Salusky, "CoronaryArtery Calcification in Young Adults with End-Stage Renal Disease who are Undergoing Dialysis,” The New England Journal of Medicine, Vol. 342, No. 20, 2000, pp. 1478-1483. doi:10.1056/NEJM200005183422003 
[15] J. A. Delmez, C. A. Tindira, D. W. Windus, K. Y. Norwood, K. S. Giles, T. L. Nighswander and E. Slatopolsky, "Calcium Acetate as a Phosphorus Binder in Hemodialysis Patients," Journal of the American Society of $\mathrm{Ne}$ phrology, Vol. 3, No. 1, 1992, pp. 96-102.

[16] C. H. Hsu, “Are We Mismanaging Calcium and Phosphate Metabolism in Renal Failure?” American Journal of Kidney Diseases, Vol. 29, No. 4, 1997, pp. 641-649. doi:10.1016/S0272-6386(97)90352-8

[17] G. Eknoyan, A. Levin and N. W. Levin "Bone Metabolism and Disease in Chronic Kidney Disease," American Journal of Kidney Diseases, Vol. 42, No. 3, 2003, pp. S1201. doi:10.1016/S0272-6386(03)00905-3

[18] W. Y. Qunibi, R. E. Hootkins, L. L. McDowell, M. S. Me- yer, M. Simon, R. O. Garza, R. W. Pelham, M. V. Cleveland, L. R. Muenz, D. Y. He and C. R. Nolan, “Treatment of Hyperphosphatemia in Hemodialysis Patients: The Calcium Acetate Renagel Evaluation (CARE Study)," Kidney International, Vol. 65, No. 5, 2004. pp. 1914-1926. doi:10.1111/j.1523-1755.2004.00590.x

[19] C. B. Boss and K. J. Fredeen, "Concepts, Instrumentation and Techniques in Inductively Coupled Plasma Optical Emission Spectrometry,” 3rd Edition, Perkin Elmer, Waltham, 1997.

[20] P. W. J. M. Boumans, "Inductively Coupled Plasma Emission Spectroscopy-Part 2,” In: P. J. Elving and J. D. Winefordner, Eds., Chemical Analysis, John Wiley \& Sons, New York, Vol. 90, 1987. 